NASA

Technical Memorandum 107145
Army Research Laboratory Technical Report ARL-TR-970

\title{
Detecting Gear Tooth Fatigue Cracks in Advance of Complete Fracture
}

James J. Zakrajsek

Lewis Research Center

Cleveland, Ohio

and

David G. Lewicki

Vehicle Propulsion Directorate

U.S. Army Research Laboratory

Lewis Research Center

Cleveland, Ohio

Prepared for the

1996 Technology Showcase on Integrated Monitoring,

Diagnostics and Failure Prevention.

sponsored by the Society for Machinery Failure Prevention Technology

Mobile, Alabama, April 22-26, 1996

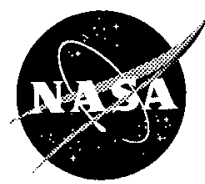

National Aeronautics and

Space Administration

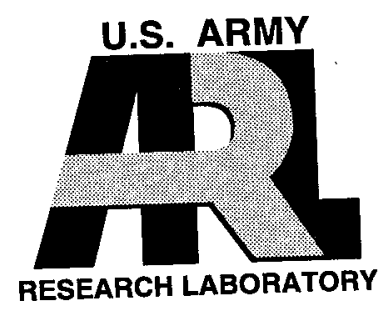




\title{
DETECTING GEAR TOOTH FATIGUE CRACKS IN ADVANCE OF COMPLETE FRACTURE
}

\author{
James J. Zakrajsek \\ National Aeronautics and Space Administration \\ Lewis Research Center \\ Cleveland, Ohio 44135 \\ and \\ David G. Lewicki \\ U.S. Army Research Laboratory \\ Lewis Research Center \\ Cleveland, Ohio 44135
}

\begin{abstract}
Results of using vibration-based methods to detect gear tooth fatigue cracks are presented. An experimental test rig was used to fail a number of spur gear specimens through bending fatigue. The gear tooth fatigue crack in each test was initiated through a small notch in the fillet area of a tooth on the gear. The primary purpose of these tests was to verify analytical predictions of fatigue crack propagation direction and rate as a function of gear rim thickness. The vibration signal from a total of three tests was monitored and recorded for gear fault detection research. The damage consisted of complete rim fracture on the two thin rim gears and single tooth fracture on the standard full rim test gear. Vibration-based fault detection methods were applied to the vibration signal both on-line and after the tests were completed. The objectives of this effort were to identify methods capable of detecting the fatigue crack, and determine how far in advance of total failure positive detection was given. Results showed that the fault detection methods failed to respond to the fatigue crack prior to complete rim fracture in the thin rim gear tests. In the standard full rim gear test all of the methods responded to the fatigue crack in advance of tooth fracture; however, only three of the methods responded to the fatigue crack in the early stages of crack propagation.
\end{abstract}

Key Words: Gear; Fatigue; Diagnostics; Failure prediction

Introduction: Drive train diagnostics is one of the most significant areas of research in rotorcraft propulsion. The need for a reliable health and usage monitoring system for the propulsion system can be seen by reviewing rotorcraft accident statistics. An investigation of serious rotorcraft accidents that were a result of fatigue failures showed that 32 percent were due to engine and transmission components [1]. In addition, governmental aviation authorities are demanding that in the near future the safety record of civil helicopters must match that of conventional fixed-wing jet aircraft. 
This would require a thirtyfold increase in helicopter safety. Practically, this can only be accomplished with the aid of a highly reliable, on-line Health and Usage Monitoring (HUM) system. A key performance element of a HUM system is to determine if a fault exists, as early and reliably as possible. Research is thus needed to develop and prove various fault detection concepts and methodologies.

For rotorcraft transmissions, a critical element of a reliable HUM system is the accurate detection of gear tooth damage. A gear tooth fatigue crack, if undetected, can propagate into complete tooth fracture or gear rim fracture, both of which can result in a potentially catastrophic failure of the transmission system. This paper addresses this mode of gear failure by applying gear fault detection techniques to vibration data from several spur gear crack propagation fatigue tests, in which crack length was monitored using special crack gages.

A number of methods have been proposed to provide early detection of gear tooth damage. Method FM4 was developed by Stewart [2] to detect isolated damage on gear teeth. Methods NA4 and NB4 were developed at NASA Lewis $[3,4]$ to detect general damage on gear teeth. McFadden [5] proposed a method to detect gear tooth cracks using the instantaneous phase of the demodulated time signal. A variation of the energy ratio reported by Swansson [6] was constructed to detect damage using the energy in the frequency spectrum. Ma [7] proposed using the energy operator to track the non-linear energy associated with a damaged gear. Verification of these detection methods with experimental vibration data along with a comparison of their relative performance is an integral step in the overall development of an accurate means to detect gear tooth damage.

In the view of the above, it becomes the objective of this research to determine the relative performance of the detection methods as they are applied to experimental data from a spur gear fatigue rig at NASA Lewis. The vibration signal from three spur gear crack propagation tests were monitored and recorded. The primary purpose of these tests was to verify analytical predictions of fatigue crack propagation direction and rate as a function of gear rim thickness [8]. Two of the tests used thin rim gears, which resulted in complete rim fracture. One test used a standard full rim test gear, which resulted in complete tooth fracture. Results of each gear fault detection method are compared, and overall conclusions are made regarding the performance of the methods in detecting the fatigue cracks in advance of total fracture.

Theory of Fault Detection Methods: All of the methods in this investigation utilized vibration data that was processed as it was collected. The vibration data was converted to digital form and time synchronously averaged to eliminate noise and vibration incoherent with the period of revolution of the spur test gear. The averaged data was then resampled by linear interpolation to provide exactly 1024 samples over two complete revolutions of the test gear. This was done to optimize the frequency resolution when converting the data to the frequency domain. This averaged and resampled data was used as the input to the diagnostic methods discussed below.

FM4 was developed to detect changes in the vibration pattern resulting from damage on a limited number of teeth [2]. A difference signal is first constructed by removing the regular meshing components (shaft frequency and harmonics, primary meshing frequency and harmonics along with their first order sidebands) from the time-averaged signal. The fourth normalized statistical moment (normalized kurtosis) is then applied to this difference signal. For a gear in good condition the 
difference signal would be primarily Gaussian noise, resulting in a normalized kurtosis value of 3 (nondimensional). When one or two teeth develop a defect (such as a crack, or pitting), a peak or series of peaks appear in the difference signal, causing the normalized kurtosis value to increase beyond the nominal value of 3 .

NA4 is a method developed at NASA Lewis Research Center to detect the onset of damage, and also to continue to react to the damage as it increases [3]. A residual signal is first constructed by removing the regular meshing components (shaft frequency and harmonics, primary meshing frequency and harmonics) from the time-averaged signal. The fourth statistical moment of the residual signal is then divided by the current run time averaged variance of the residual signal, raised to the second power. This operation normalizes the kurtosis in NA4; however, it is normalized using the variance of the residual signal averaged over the run up to the current time record, where NA4 is being calculated. With this method, the changes in the residual signal are constantly being compared to a weighted baseline for the specific system in "good" condition. This allows NA4 to grow with the severity of the fault until the average of the variance itself changes. NA4 is dimensionless, with a value of 3 , under nominal conditions.

NB4 is another parameter recently developed at NASA Lewis [4]. NB4 is similar to NA4 in that it uses the same operation to normalize the kurtosis. The major difference is that instead of using a residual signal, NB4 uses the envelope of a bandpassed segment of the signal. NB4 is a demodulation technique, in which the signal is first band-pass filtered about the dominant meshing frequency. A bandwidth of \pm 17 sidebands was used for the spur gear tests. Using the Hilbert transform, a complex time signal is then created in which the real part is the band-pass signal, and the imaginary part is the Hilbert transform of the signal. The envelope is the magnitude of this complex time signal and represents an estimate of the amplitude modulation present in the signal due to the sidebands. Amplitude modulation in a signal is most often due to periodically reoccurring transient variations in the loading. The theory behind this method is that a few damaged teeth will cause transient load fluctuations which can be observed in the envelope of the signal. NB4 is also dimensionless, with a value of 3 under nominal conditions.

Another demodulation technique was developed to detect local gear defects, such as gear tooth fatigue cracks [5]. The basic theory behind this technique is that a gear tooth defect will produce sidebands that modulate the dominant meshing frequency. In this method the signal is band-passed filtered about a dominant meshing frequency, including as many sidebands as possible. The Hilbert transform is then used to convert the real bandpassed signal into a complex time signal or analytic signal. Using the real and imaginary parts of the analytic signal, the instantaneous phase (I.P) can be estimated from the filtered sidebands. Teeth with a fatigue crack will cause a lead or lag in tooth contact during meshing, resulting in transient changes in the gear rotation. These transient changes in rotation will dominate the I.P. function. The peak-to-peak level of the instantaneous phase over one complete revolution of the gear is then determined in order to quantify the relative variance of the I.P. at each point in the run.

One method investigated is a variation of the energy ratio technique [6]. The energy ratio was originally constructed to be a robust indicator of heavy uniform wear. The energy ratio is found by dividing the standard deviation of the difference signal by the standard deviation of the regular meshing components, as defined previously. In this study, the energy ratio is found by dividing the 
sum of the non-mesh related amplitudes in the frequency spectrum by the sum of the mesh related amplitudes (meshing frequencies plus first 6 sidebands). This parameter was used to quantify the trend seen in the frequency spectrum of increasing amplitudes at non-mesh related frequencies as the damage increased.

A technique using the "energy operator" was also investigated in this study. First developed for speech production modeling, the energy operator was recently proposed for gear defect detection recently by $\mathrm{Ma}$ [7]. The energy operator is a non-linear function that reacts to impulsive energy in a vibration signal. An impulse in the time-averaged vibration signal caused by a damaged gear tooth is reinforced by the energy operator, thus allowing the impulse to be more easily detected. In this study, the time averaged signal is first band-passed filtered about the primary meshing frequency using \pm 20 sidebands. The discrete form of the energy operator, as given in Ref. 7 is then applied to the band-passed signal. In order to detect any reinforced impulsive events in the energy operator, the normalized kurtosis is then applied to the energy operator results. The normalized kurtosis, as described earlier, reduces the results to one nondimensional number with the value of 3 under nominal conditions.

Apparatus and Gear Damage Review: The spur gears shown in Figs. 1 and 2 were part of a series of crack propagation tests conducted on a spur gear fatigue test rig at NASA Lewis Research Center. To initiate cracks, a notch was placed in the fillet region (loaded side) on one tooth of each of the test gears. The notches were located at a radius of $40.49 \mathrm{~mm}$ (1.594 in.) on the fillet, which is the position of the maximum tensile stress. The spur gear test rig was then used to fail the spur gear specimen through bending fatigue. The primary purpose of these tests was to verify analytical predictions of fatigue crack propagation direction and rate as a function of gear rim thickness [8]. To verify the crack growth rate, crack detection gages were installed on each side of the tooth with the notch. As the crack propagated it broke through each of the nine crack wires that circumferentially surrounded the fillet area on each side. The nine crack wires cover the first $1.62 \mathrm{~mm}(0.064 \mathrm{in}$.) of crack length, thus allowing the crack magnitude and rate to be recorded as a function of cycles, or run time. During the tests, vibration data from an accelerometer mounted on the gear shaft bearing housing was captured using an on-line program running on a personal computer with an analog to digital conversion board and anti-aliasing filter. The 28-tooth instrumented test spur gear meshes with a 28-tooth standard rim spur gear at a nominal speed of $10000 \mathrm{rpm}$ in the fatigue test rig. The spur gears have a face width of $6.35 \mathrm{~mm}(0.25 \mathrm{in}$.) and a pitch diameter of $88.9 \mathrm{~mm}$ (3.50 in.). Each test started with a one hour break-in period at a low load level, after which the load was increased and the test continued until complete fracture occurred. A test load of $89 \mathrm{~N}-\mathrm{m}$ (786 in-lbs) was used for runs 1 and 2. For run 3, a test load of $136 \mathrm{~N}-\mathrm{m}$ (1200 in-lbs) was used.

Runs 1 and 2 used the thin rim gear geometry illustrated in Fig. 1. Crack length, as recorded by the crack gages, is plotted as a function of run time for run 1 in Fig. 3 . The first hour was the break-in period, thus the crack started on the rear side only at approximately 1.75 hours after full load was applied. As seen in this figure, the crack gages cover approximately the first $50 \%$ of the total crack length to failure. For runs 1 and 2, failure is defined as the complete fracture of the gear rim, as seen in Fig. 1. The lines connecting the last crack gage points to failure is for reference purposes only. Due to instrumentation problems the crack gages did not function correctly for run 2 , and no crack length plot is available. 
Run 3 used the full rim gear geometry illustrated in figure 2. Crack length is plotted as a function of run time for run 3 in figure 4 . The break-in period is not included in this plot, thus the crack started shortly after the full load was applied. In this run, the crack gages cover only the first $18 \%$ of the total crack length to failure. For run 3 failure is defined as complete fracture of the tooth, as seen in figure 2 . Although the crack gages only cover $18 \%$ of the total crack length, they cover $75 \%$ of the time from the start of the crack to failure. Two regions can be seen in figure 4, with the first representing a moderate crack growth rate (first $75 \%$ of propagation time). The last $25 \%$ of the crack propagation time represents a region of accelerated crack growth rate, where the final $82 \%$ of total crack length is achieved.

Discussion of Results: Results of applying the diagnostic methods to crack propagation runs 1, 2, and 3 are illustrated in Figs. 5, 6, and 7, respectively. Figure 8 gives the frequency spectrum of the time-averaged signal for each of the runs at the start of each test, following the one hour break-in period. Figure 9 illustrates the time-averaged vibration plots for the last data point (end of test point) from each of the runs. The vibration plots in this figure are over one complete revolution of the test gear.

Based on the results, the gear fault detection methods were unable to give early indication of the fatigue crack in the thin rim gear tests. As seen in Fig. 5, the diagnostic parameters were applied to the vibration data from run 1 after the initial one hour break-in period. Each of the parameters are plotted as a function of run time and, at the top of the plots, as a function of crack length also. As seen in Fig. 5, with the exception of the kurtosis of the energy operator, only parameters NA4 (Fig. 5(b)) and NB4 (Fig. 5(c)) reacted to the damage. However, NA4 and NB4 were unable to detect the crack until complete rim fracture resulted, thus giving no advanced warning of the impending failure. The kurtosis of the energy operator appears to have reacted to the crack early in the run, as seen in Fig. 5(f). This very large reaction at the start of crack propagation is not repeated in runs 2 and 3. It is unclear at this time as to why this ideal type of reaction occurred only on run 1. Figure 6 plots the results of the parameters for run 2, also a thin rim gear test. Although no crack propagation plot is available for this run, the results are similar to those seen in run 1 . The fault detection methods give positive indication of the damage only at or near completion of the test.

All of the gear fault detection methods reacted to the fatigue crack prior to complete tooth fracture in the full rim spur gear test. The plots in Fig. 7 do not include the initial one hour break-in period for run 3. Each of the parameters are plotted as a function of run time, and as a function of crack length (top of plot). As seen in Fig. 7, all of the parameters react substantially to the crack in the region of accelerated crack growth. As stated earlier this is the region where the last $82 \%$ of total crack length is achieved in only $25 \%$ of the total crack growth time. Of the normalized, nondimensional parameters, NB4 peaks at a value of 107, the kurtosis of the energy operator peaks at 32, NA4 peaks at 17, and FM4 peaks at a value of 5 . All of these parameters are referenced to the value of 3 under nominal conditions.

Although all of the methods were able to detect the crack during the last stage of crack propagation in run 3, more advanced warning of the crack is needed for this potentially catastrophic event. As seen in Fig. 7, NA4 (Fig. 7(b)), NB4 (Fig. 7(c)), and the kurtosis of the energy operator (Fig. 7(f)) are the only parameters that show an increasing trend above the nominal value during the first phase of crack propagation. A method of establishing an exceedance level was used to determine 
relative warning times for the three parameters. This method uses a value of five standard deviations over the mean value for the exceedance level, where the mean level and standard deviation are based on the data prior to crack growth [9]. As seen in Fig. 7(f), based on this exceedance level, the kurtosis of the energy operator gives the earliest warning of damage. It reaches the exceedance level at 0.083 hours, or at $46 \%$ of the total crack propagation time, at which the crack has only advanced to approximately $7 \%$ of its total length. As seen in Figs. 7(b) and (c), NA4 and NB4 reach the exceedance level at 0.111 hours, or at $62 \%$ of total crack propagation time, at which the crack has only advanced to approximately $11 \%$ of its total length. The warning times based on these three parameters are nearly twice as long as that given by the other fault detection methods. In addition, NA4, NB4, and kurtosis of the energy operator were able to detect the crack during the more moderate crack growth rate region.

The additional compliance associated with the thin rim gears along with the geometry of these gears may have inhibited the parameters from detecting the fatigue crack in runs 1 and 2 . Figure 8 plots the frequency spectrum of the first data point after the break-in period for each run. The spectrums from the thin rim gear tests, Figs. 8(a) and (b), show a more complex frequency distribution as compared to the spectrum from the full rim gear test (Fig. 8(c)). As seen in Fig. 8(c), the frequency spectrum is primarily composed of the primary gear mesh frequency $(\mathrm{fl}=4.7 \mathrm{kHz})$, harmonics of the mesh frequencies, and the corresponding sidebands about these frequencies. The non-uniform geometry of the thin rim gear coupled with the added compliance associated with the thin rim will tend to produce a more complex meshing pattern than a standard rim gear. This is illustrated in the plots shown in Fig. 9. All of the plots in this figure are of the last data point for each run, thus complete rim fracture has occurred for runs 1 and 2 (Figs. 9(a) and (b)), and complete tooth fracture has occurred for run 33 (Fig. 9(c)). The tooth fracture induced impulse seen in Fig. 9(c) is clearly visible and highly localized. The rim fracture induced impulse seen in Figs. 9(a) and (b) are nonlocalized and much more difficult to distinguish in the signal. The additional flexibility of the thin rim gears may not allow the cracked tooth to create the impulse in the vibration signal, and thus compensates for the fault until complete fracture. In addition, the nonuniform geometry of the thin rim gear complicates the vibration signal, possibly masking the dynamics of the tooth crack.

Conclusions: Based on the results of applying a variety of gear fault detection techniques to experimental data from spur gear crack propagation tests, the following conclusions can be made.

(1) In the thin-rim spur gear tests, the gear fault detection techniques investigated were unable to give early indication of the fatigue crack prior to rim fracture. The additional compliance associated with the thin-rim gears may have compensated for the crack, thus minimizing the dynamic influence of the crack on the vibration signal until total rim fracture.

(2) In the full rim spur gear test, all of the techniques investigated reacted to the fatigue crack, in varying degrees, prior to complete tooth fracture. The more robust reactions to the fatigue crack occurred in the last stages of crack propagation, as the crack accelerated to complete fracture.

(3) The methods NA4, NB4, and the energy operator gave the earliest reactions to the fatigue crack in the standard spur gear test. These techniques reacted to the fatigue crack during the early stages, as the crack was growing at a moderate rate. 


\section{References:}

1. Astridge, D.G.: Helicopter Transmissions - Design for Safety and Reliability. Inst. Mech. Eng. Proc., Pt. G-J Aerosp. Eng. vol. 203, no. G2, 1989, pp. 123-138.

2. Stewart, R.M.: Some Useful Data Analysis Techniques for Gearbox Diagnostics. Report MHM/ R/10/77, Machine Health Monitoring Group, Institute of Sound and Vibration Research, University of Southampton, July 1977.

3. Zakrajsek, J.J.; Townsend, D.P.; Decker, H.J.; An Analysis of Gear Fault Detection Methods as Applied to Pitting Fatigue Failure Data. Proceedings of the 47th Meeting of the Mechanical Failures Prevention Group. Office of Naval Research, Arlington, VA., 1993, pp. 199-208.

4. Zakrajsek, J.J.; Handschuh, R.F.; and Decker, H.J.: Application of Fault Detection Techniques to Spiral Bevel Gear Fatigue Data. Proceedings of the 48th Meeting of the Mechanical Failures Prevention Group. Office of Naval Research, Arlington, VA., 1994, pp. 93-104.

5. McFadden, P.D.: Detecting Fatigue Cracks in Gears by Amplitude and Phase Demodulation of the Meshing Vibration. J. Vib. Acoust. Stress Reliab. Design, vol. 108, no. 2, April, 1986, pp.165-170.

6. Swansson, N.S.: Application of Vibration Signal Analysis Techniques to Signal Monitoring. Conference on Friction and Wear in Engineering 1980, Institute of Engineers, Australia. Barton, Australia, 1980, pp. 262-267.

7. Ma, J.: Energy Operator and Other Demodulation Approaches to Gear Defect Detection. Proceedings of the 49th Meeting of the Society for Machinery Failure Prevention Technology. Vibration Institute, Willobrook, Illinois, 1995, pp. 127-140.

8. Lewicki, D.G.: Crack propagation Studies to Determine Benign or Catastrophic Failure Modes for Aerospace Thin-Rim Gears. Ph.D. Dissertation, Case Western Reserve University, May 1995.

9. Rose, H.J.: Vibration Signature and Fatigue Crack Growth Analysis of a Gear Tooth Bending Fatigue Failure. Proceedings of the 44th Meeting of the Mechanical Failure Prevention Group. Office of Naval Research, Arlington, Virginia, 1990. 


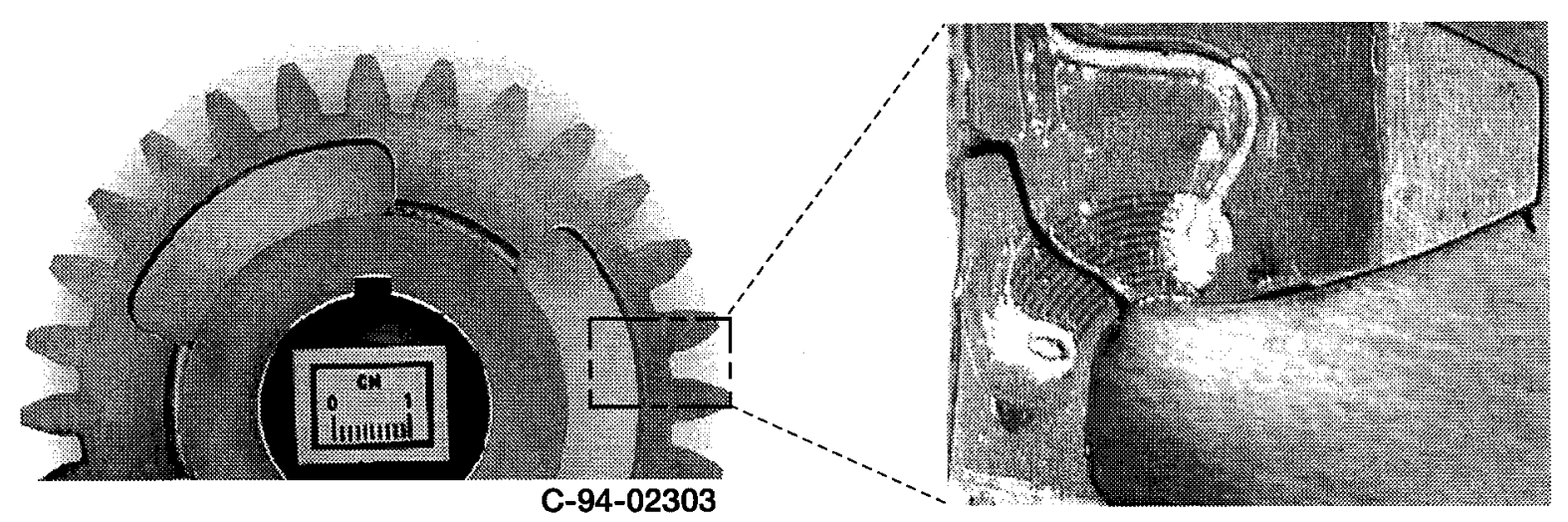

Figure 1.-Gear geometry configuration for runs 1 and 2.

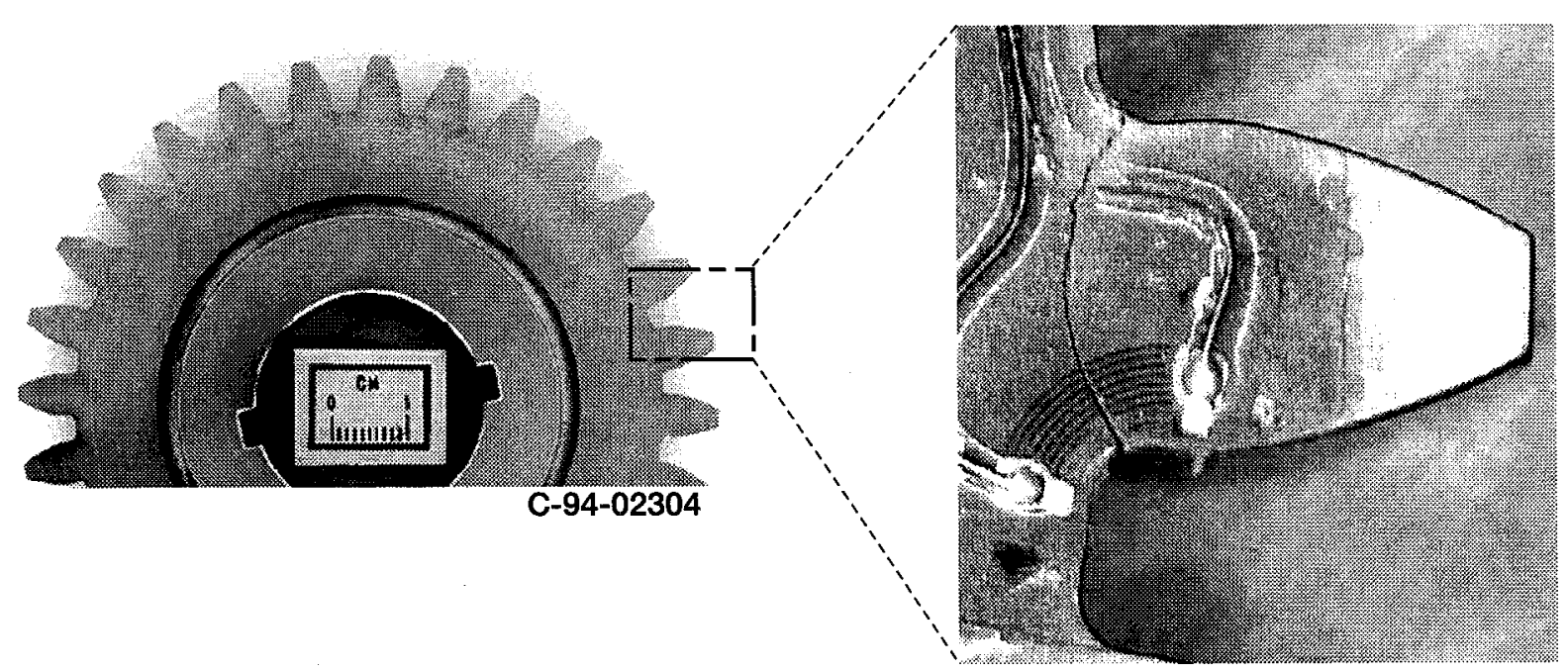

Figure 2.-Gear geometry configuration for run 3.

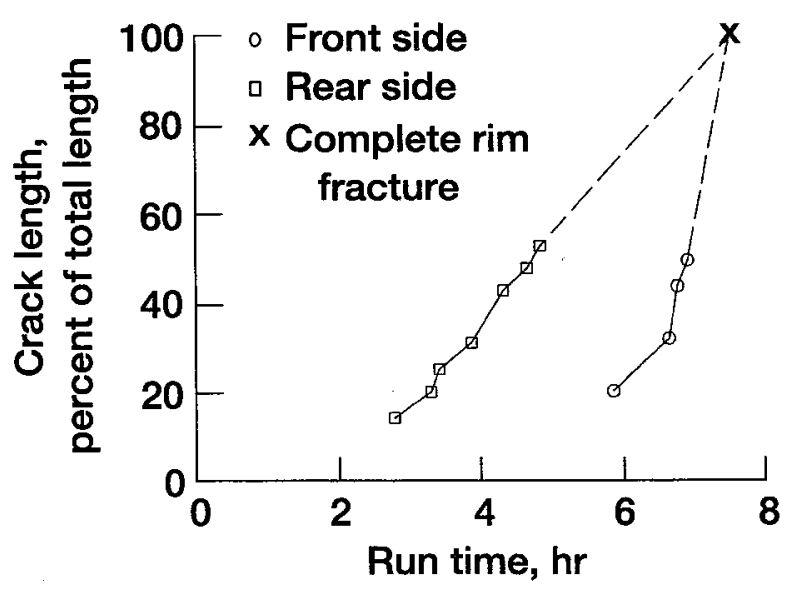

Figure 3.-Crack length as a function of run time for run 1.

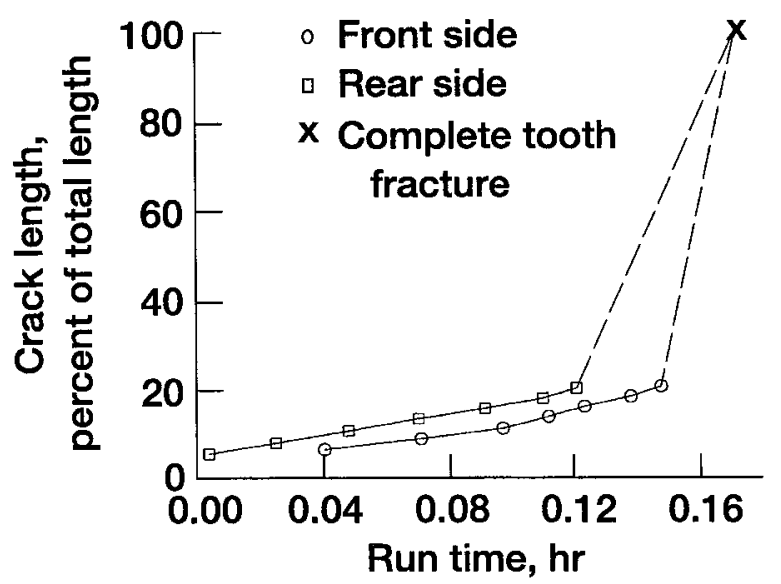

Figure 4.-Crack length as a function of run time for run 3. 
Crack length

(percent of total length to fracture,

front (F) \& rear (R) gages)

50

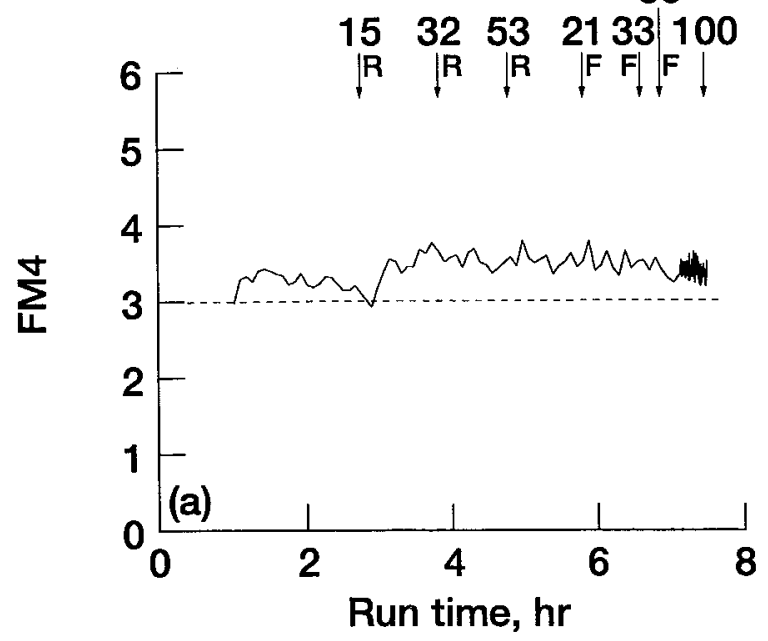

50

\begin{tabular}{lllll|l}
15 & 32 & 53 & 2133 & 100
\end{tabular}

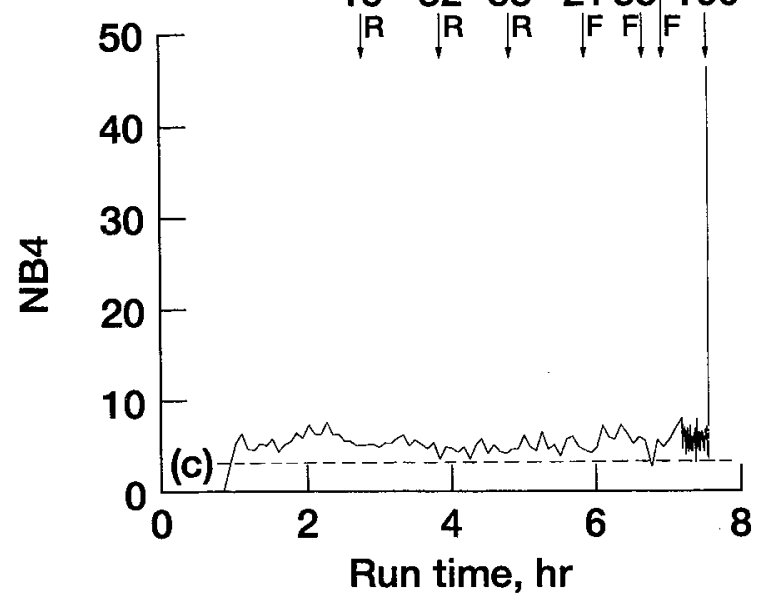

50

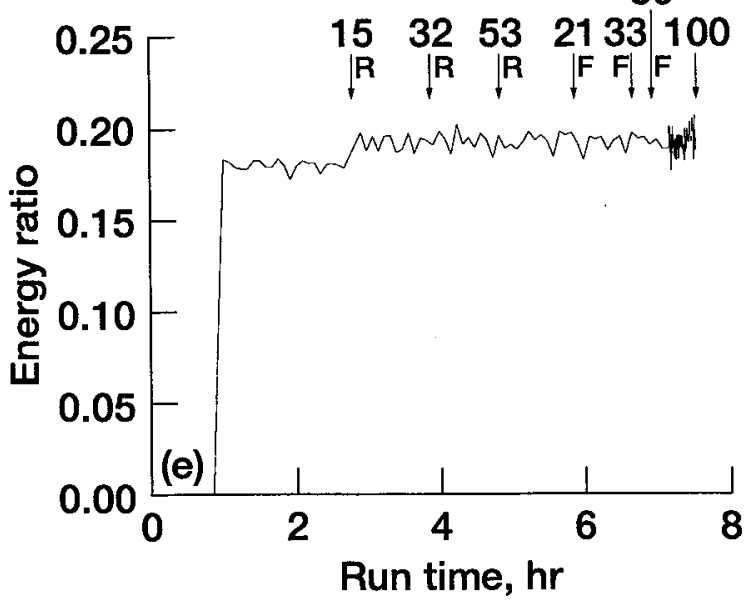

Crack length

(percent of total length to fracture, front (F) \& rear (R) gages)

50

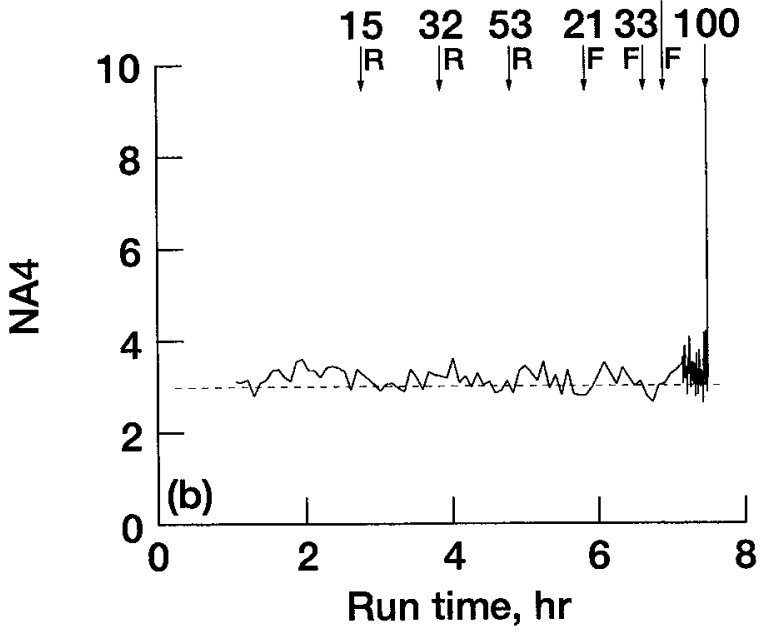

50

\begin{tabular}{lllll|l}
15 & 32 & 53 & 2133 & 100
\end{tabular}

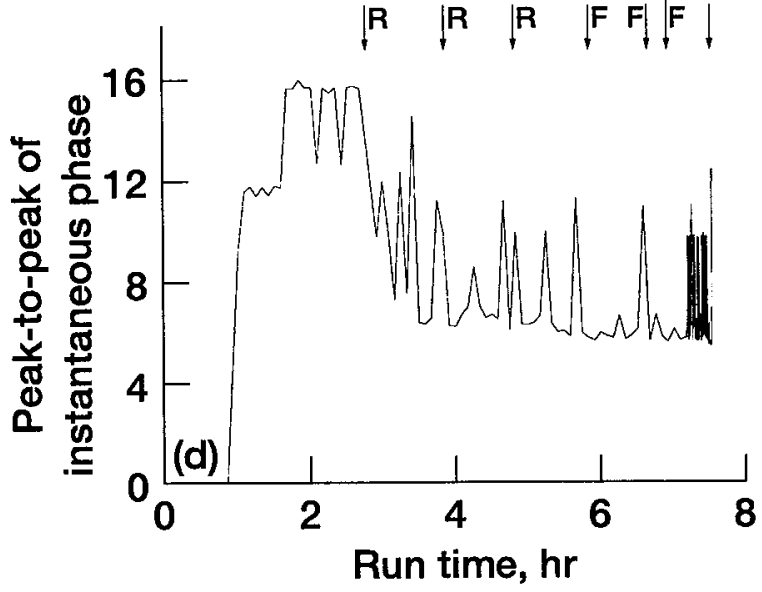

50

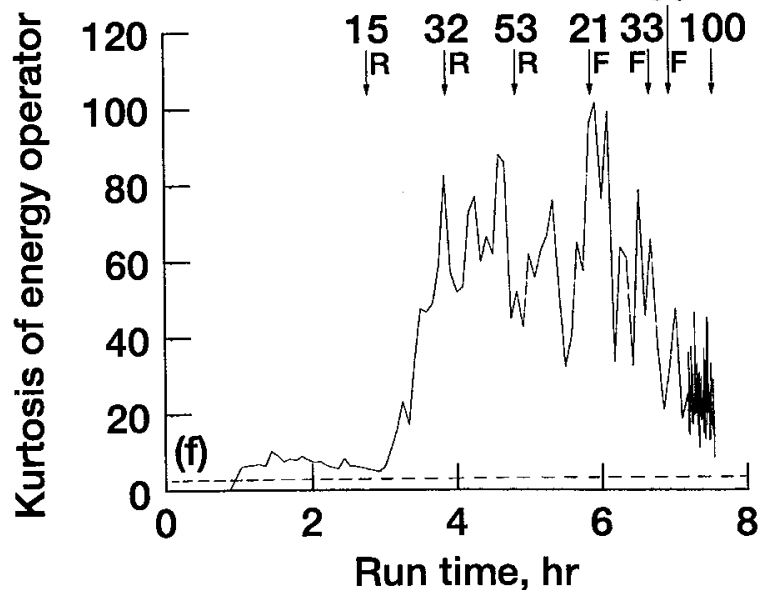

Figure 5.-Response of gear fault detection parameters for run 1. 

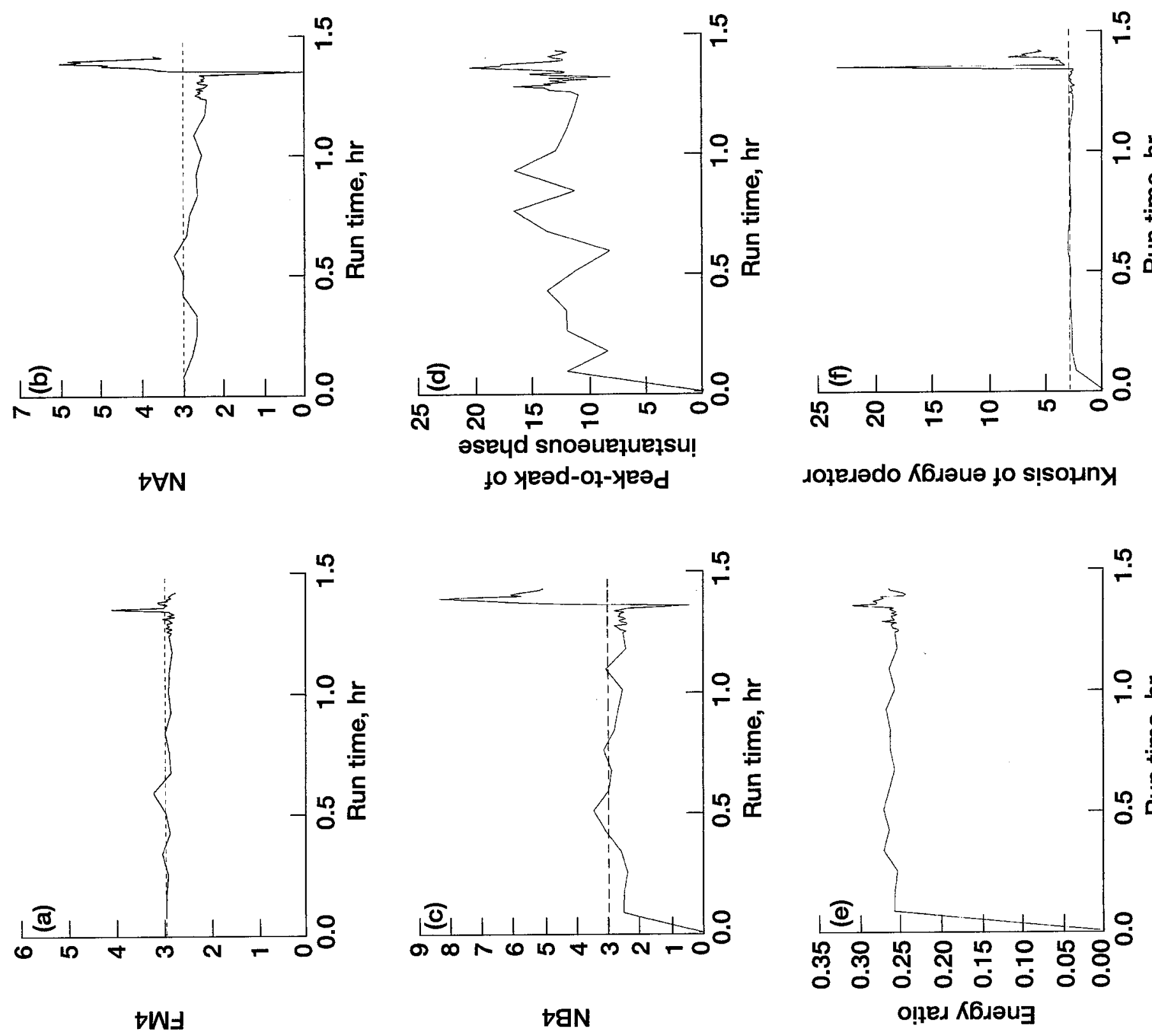

دołejədo K6.əuə to s!̣souny

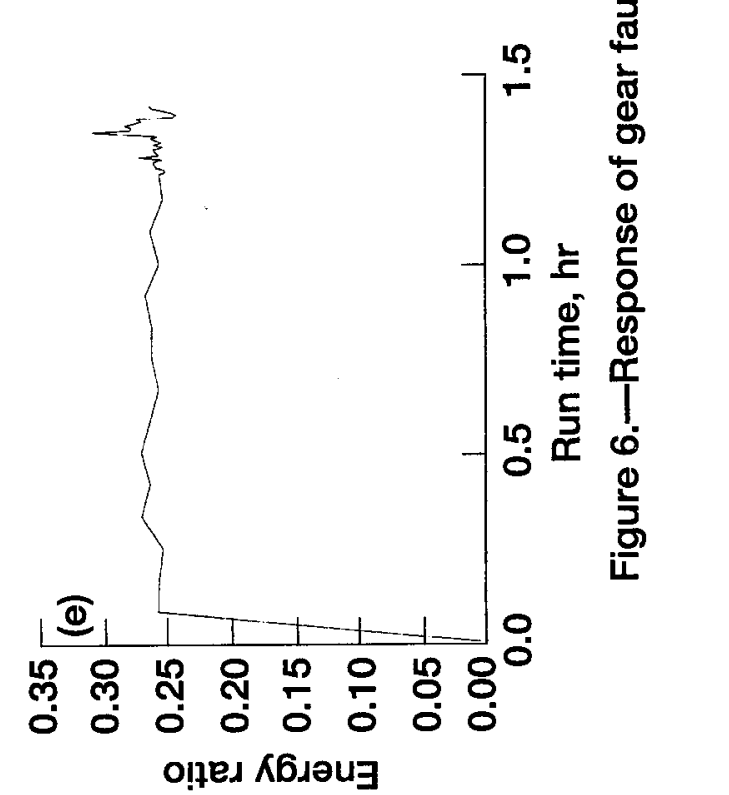


Crack length

(percent of total length to fracture, front gage) 1115

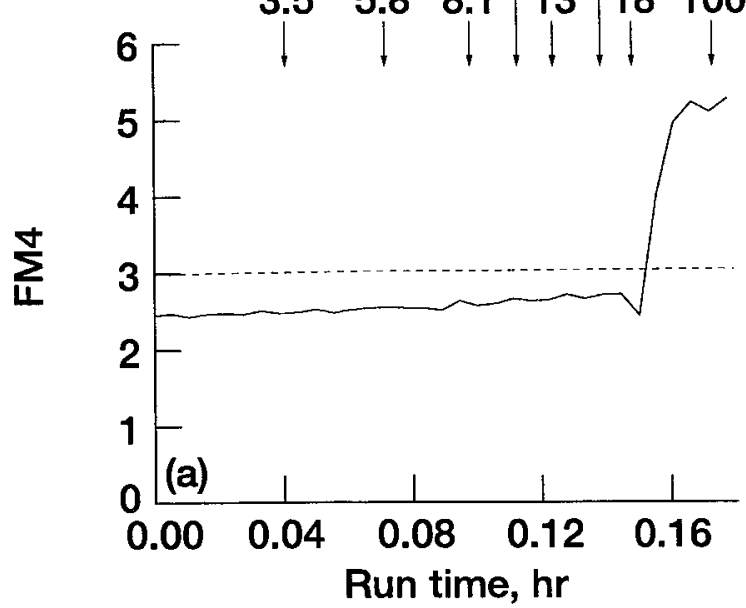

1115

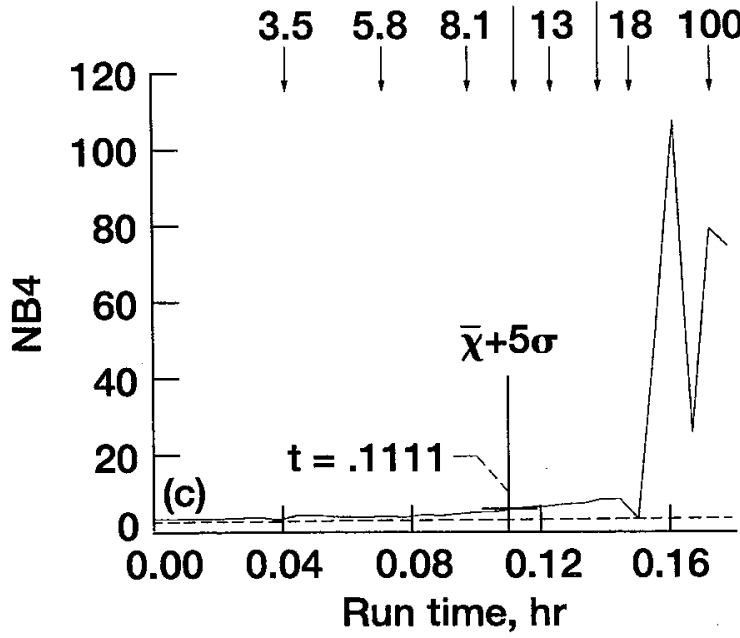

1115

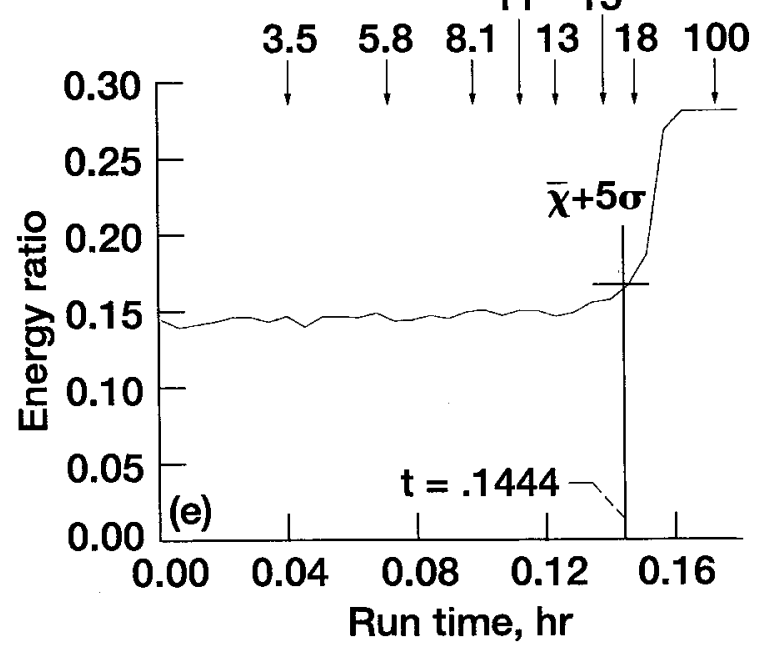

Crack length

(percent of total length to fracture, front gage) 1115

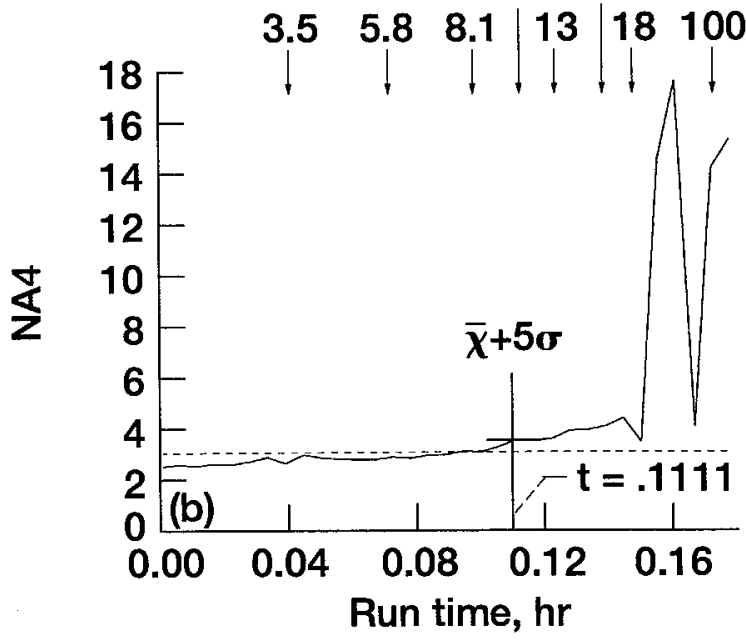

1115
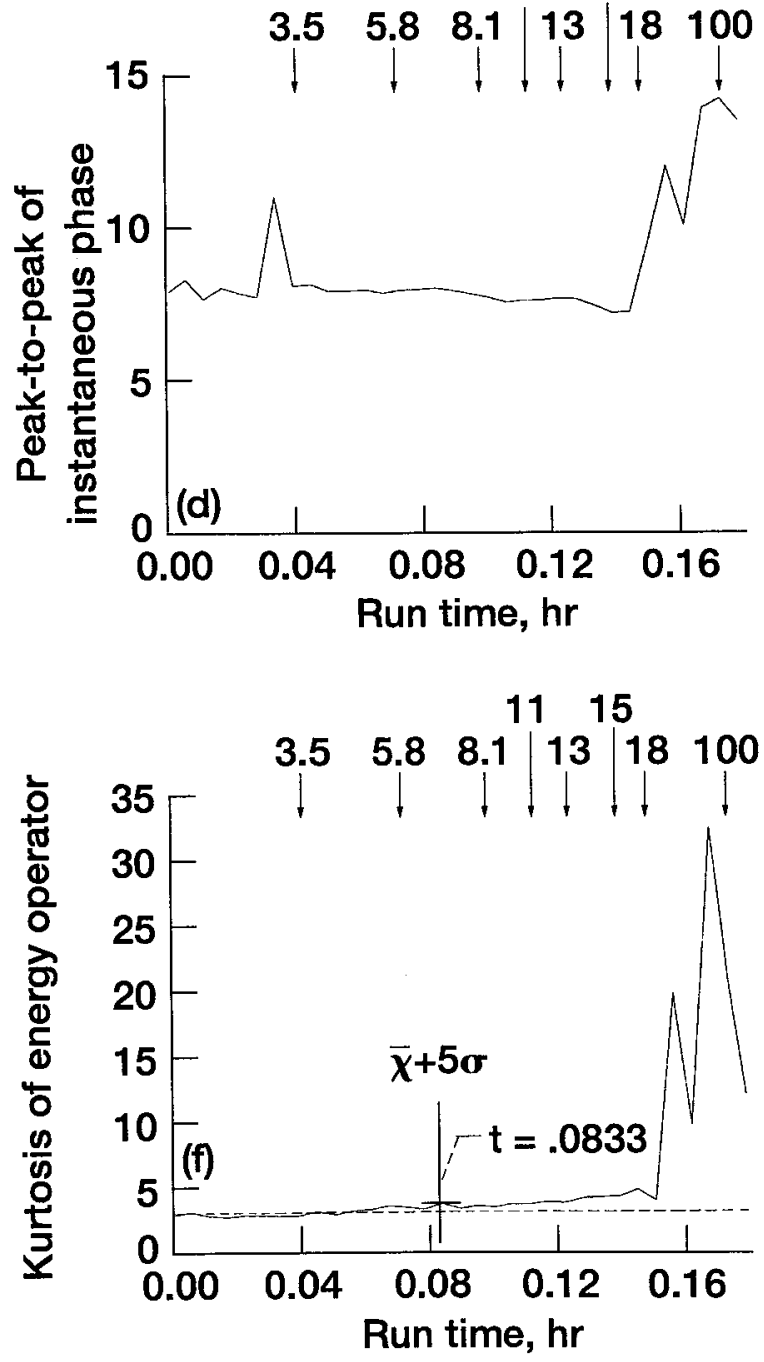

Figure 7.-Response of gear fault detection parameters for run 3. 

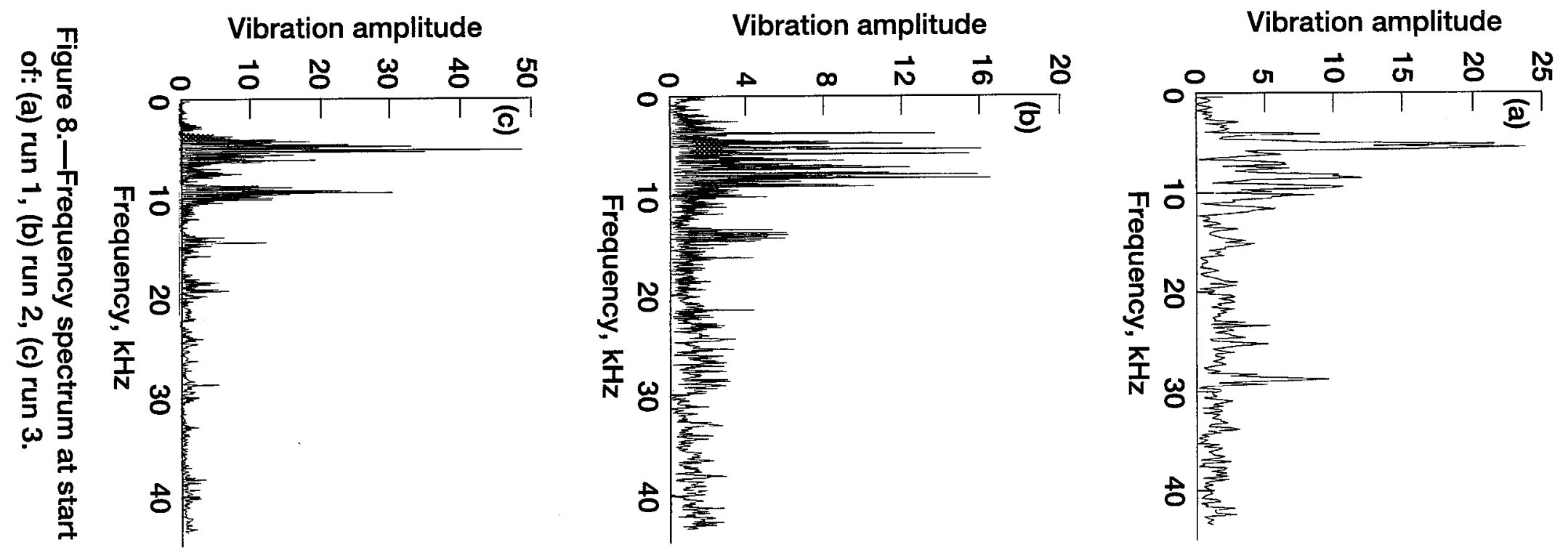

$N$
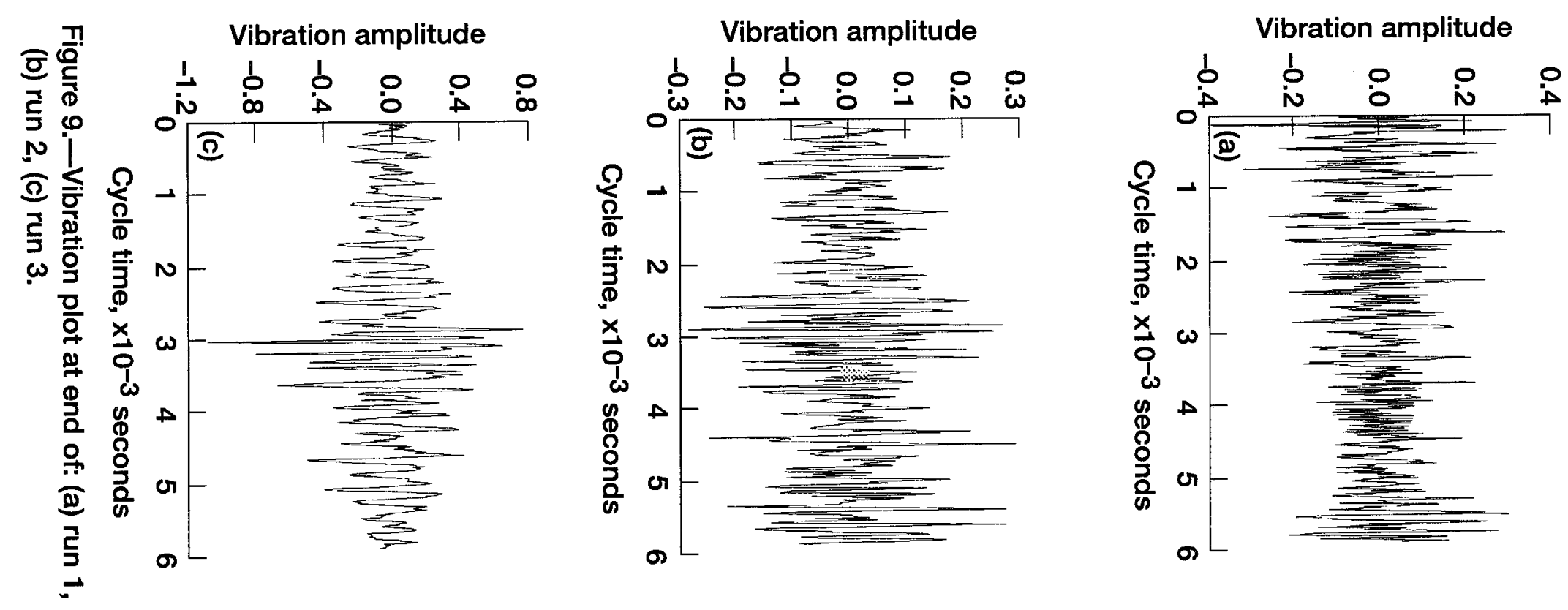
Public reporting burden for this collection of information is estimated to average 1 hour per response, including the time for reviewing instructions, searching existing data sources, gathering and maintaining the data needed, and completing and reviewing the collection of information. Send comments regarding this burden estimate or any other aspect of this collection of information, including suggestions for reducing this burden, to Washington Headquarters Services, Directorate for Information Operations and Reports, 1215 Jefferson Davis Highway, Suite 1204, Arlington, VA 22202-4302, and to the Office of Management and Budget, Paperwork Reduction Project (0704-0188), Washington, DC 20503.

\begin{tabular}{|l|c|c|}
\hline 1. AGENCY USE ONLY (Leave blank) & $\begin{array}{c}\text { 2. REPORT DATE } \\
\text { January } 1996\end{array}$ & $\begin{array}{r}\text { 3. REPORT TYPE AND DATES COVERED } \\
\text { Technical Memorandum }\end{array}$ \\
\hline
\end{tabular}

4. TITLE AND SUBTITLE

Detecting Gear Tooth Fatigue Cracks in Advance of Complete Fracture

6. AUTHOR(S)

James J. Zakrajsek and David G. Lewicki

\section{FUNDING NUMBERS}

\section{PERFORMING ORGANIZATION NAME(S) AND ADDRESS(ES)}

NASA Lewis Research Center

Cleveland, Ohio 44135-3191

and

Vehicle Propulsion Directorate

U.S. Army Research Laboratory

Cleveland, Ohio 44135-3191

9. SPONSORING/MONITORING AGENCY NAME(S) AND ADDRESS(ES)

National Aeronautics and Space Administration

Washington, D.C. 20546-0001

and

U.S. Army Research Laboratory

Adelphi, Maryland 20783-1145
WU-505-62-36

1L162211A47A

\section{SUPPLEMENTARY NOTES}

Prepared for the 1996 Technology Showcase on Integrated Monitoring, Diagnostics and Failure Prevention sponsored by the Society for Machinery Failure Prevention Technology, Mobile, Alabama, April 22-26, 1996. James J. Zakrajsek, NASA Lewis Research Center and David G. Lewicki, Vehicle Propulsion Directorate, U.S.Army Research Laboratory, NASA Lewis Research Center. Responsible person, James J. Zakrajsek, organization code 2730, (216) 433-3968.

12a. DISTRIBUTION/AVAILABILITY STATEMENT

8. PERforming organization REPORT NUMBER

E-10075

10. SPONSORING/MONITORING AGENCY REPORT NUMBER

NASA TM-107145

ARL-TR-970

Unclassified - Unlimited

Subject Category 37

This publication is available from the NASA Center for Aerospace Information, (301) 621-0390.

13. ABSTRACT (Maximum 200 words)

Results of using vibration-based methods to detect gear tooth fatigue cracks are presented. An experimental test rig was used to fail a number of spur gear specimens through bending fatigue. The gear tooth fatigue crack in each test was initiated through a small notch in the fillet area of a tooth on the gear. The primary purpose of these tests was to verify analytical predictions of fatigue crack propagation direction and rate as a function of gear rim thickness. The vibration signal from a total of three tests was monitored and recorded for gear fault detection research. The damage consisted of complete rim fracture on the two thin rim gears and single tooth fracture on the standard full rim test gear. Vibrationbased fault detection methods were applied to the vibration signal both on-line and after the tests were completed. The objectives of this effort were to identify methods capable of detecting the fatigue crack, and determine how far in advance of total failure positive detection was given. Results showed that the fault detection methods failed to respond to the fatigue crack prior to complete rim fracture in the thin rim gear tests. In the standard full rim gear test all of the methods responded to the fatigue crack in advance of tooth fracture; however, only three of the methods responded to the fatigue crack in the early stages of crack propagation.

\begin{tabular}{|c|c|c|}
\hline \multicolumn{3}{|c|}{$\begin{array}{l}\text { 14. SUBJECT TERMS } \\
\text { Gear; Fatigue; Diagnostics; Failure prediction }\end{array}$} \\
\hline $\begin{array}{l}\text { 17. SECURITY CLASSIFICATION } \\
\text { OF REPORT } \\
\text { Unclassified }\end{array}$ & $\begin{array}{l}\text { 18. SECURITY CLASSIFICATION } \\
\text { OF THIS PAGE } \\
\text { Unclassified }\end{array}$ & $\begin{array}{l}\text { 19. SECURITY CLASSIFICATION } \\
\text { OF ABSTRACT } \\
\text { Unclassified }\end{array}$ \\
\hline
\end{tabular}


National Aeronautics and

Space Administration

Lewis Research Center

21000 Brookpark Rd.

Cleveland, OH 44135-3191

Official Business

Penalty for Prlvate Use $\$ 300$

POSTMASTER: If Undeliverable - Do Not Return 